International Journal of English Literature and Social Sciences
Vol-6, Issue-1; Jan-Feb, 2021

\title{
Enhancement of Language Skills of Agriculture Graduates through a Role Play
}

\author{
Dr. Gajanan Malviya
}

Assistant Professor- Department of English, JNKVV College of Agriculture, Ganjbasoda, District-Vidisha, Madhya Pradesh, India

Received: 07 Dec 2020; Received in revised form: 11 Jan 2021; Accepted: 19 Feb 2021; Available online: 28 Feb 2021

(0)2021 The Author(s). Published by Infogain Publication. This is an open access article under the CC BY license

(https://creativecommons.org/licenses/by/4.0/).

\begin{abstract}
In the modern globalised world, every professional need good communication skills \& it is a well-known fact in modern times that, like all the other graduates, the Agriculture graduates also need them to communicate with all the stake holders of Agriculture. They need not just local languages but English language as well because it's not as a medium of instruction but as a medium of trade, commerce, communication and above all international trade. In order to be placed in a good company or organization, it's very essential that the Agriculture Graduates have command over the words. If one is clear in expressing one's thoughts and articulating one's accomplishments, he is able to make a favorable impression on the selector. The academic language ability may be sufficient to manage their course work, but they struggle to cope with the communication demands of the global market. So, there is a great need to frame course material and develop methods so as to enhance language skills of agriculture graduates. Therefore, in order to support the agriculture students with a new communicative approach, which is framed in such a way to supplement their communicative abilities, is what we are going to deal with. By applying this approach to the agriculture graduates, effective results were seen on the part of the students.
\end{abstract}

Keywords- Language skills, LSRW, Role-play, communication, discussion, professional skills, presentation.

Agricultural students - When we learn a language, there are four skills that we need for complete communication. It's quite natural for a native learner who learns his native language that they usually learn to listen first, then to speak, to read, and finally to write. These are called the four "language skills". These skills are Listening, Speaking, Reading, and Writing. When it comes to the context of first-language acquisition, all these skills are most often acquired in the sequence of listening first, then speaking, then reading and writing. Since they are learnt in a particular order by the language learner, these competencies are normally called as LSRW skills. It's obvious that an agricultural student with good language skills gets a good job. One can easily win the favour of an interviewer if one is clear in expressing his/her thoughts and articulating their accomplishments and attributes in an impressive manner. As in the opening, it is told that we are living in a globalized world and all the students in this context, especially the agriculture students, need a specific set of language skills for their success in career. Industries are also voicing their concerns about the need for better language skills among students of agriculture. In fact, the professional profile of a modern qualified Agri-graduate should include well developed communication skills and high English proficiency to help him/her achieve success in modern highly competitive global work arena.

Those agriculture graduates who have got a good command over the language skills (LSRW) lead or may have an edge over others with poor language skills when it comes to their interview and selections, because if someone lacking these skills, it's obvious that his/her chances of selection to a particular job are limited. So, in other words the knowledge of all the skills is a need of the time instead of one's choice otherwise, consequently the agriculture students may face local as well as global 
challenges from all the corners. So there is a great need to frame course material and develop methods and strategies so as to enhance language skills of Agriculture graduate.

Role Play- In the opinion of Porter-Ladousse (1987: 3), "Role play activities range from highlycontrolled guided conversations at one end of the scale, to improvised drama activities at the other; from simple rehearsed dialogue performance, to highly complex simulated scenarios." Knowing the principles of communicative activities, it is now easier to distinguish different spoken interactions.

A role-play, in modern context, can be a handy tool in the hands' of the teacher. Because its prime goal is to boost students' interaction in the classroom, educators should not forget about incorporating such a speaking activity to reflect learners' theoretical knowledge of a language in practice. We need to make them $\mathrm{Be}$ Aware, not beware of learning language. In fact the final goal of the speaking skill in the English language is primarily to communicate themselves in English. To enable the learners to communicate their thoughts, ideas, and feelings via oral language, to equip them with the necessary potentialities connected to the developing modern needs in the art of learning and improving language and usage.

There are so many techniques and tactics through which we can improve the spoken skill of the students, like giving them some spoken exercises, storytelling, drama etc. They all involve the learners to become the best communicators. One more approach to make learners actively involved and give them an opportunity to practice communicating in different contexts is a Role - play. It uses different communicative techniques and develops fluency and confidence in the learners. At the same time role play promotes interaction in the class room and increases motivation. To cut it short, we can say that role play exhibits the speakers' mind. The importance of the proverb can be established in different manners. Role play is an innovative method which brings out the hidden talents in the student and tells how he approached the main idea.

How to Use Role Play- For the agriculture students, it is easy to set up and run a role-playing session. It will help to follow the steps

1: Understanding the situation: The teacher, to start the process, may gather the students together, introduce the problem, and encourage an open discussion to uncover all of the relevant issues. This discussion will enable the learners to start thinking about the problem before the start of the actual role-play. For this it is suggested to the teacher to put the proverb on the black board. A teacher can put the proverbs told by the students on the black board.

2: Underline the details: Now the teacher sets up a scenario in enough detail for the students to feel "real". The teacher should try to make sure that everyone is very well acquainted with the problem that he is trying to work through, and that the participants know what the teacher wants to achieve by the end of the session.

3: Clarity of roles: When the teacher sets the scene, he identifies the various fictional characters involved in the scenario. It is obvious that some of them may be the people who have to deal with the actual situation as it happens in reality. In this process the other participants, as per the situation and condition, will represent those who are in support or against the proverb.

4: Allocation of roles: when the teacher has identified these roles, he will allocate them to the students involved in his exercise. The students should use their imagination and reasoning to put themselves inside the minds of the other groups.

5: Discussion -When the teacher and the students finish the role-play, there should be some discussion as to what they have learned, so that the students or the other people involved can learn from the experience. May be each group individually has to discuss the message in the proverb.

6: Change of roles: Students work on the script with different personalities, beliefs, value systems, abilities and background experiences. The script is developed on the basis of the important and thought provoking point in the proverb.

7. Selection of Topics: The script can be prepared for any situation like, 'at the restaurant',' checking in at the airport',' class room situations',' any real life situation'.

\section{The Teacher's roles in a role-play}

First of all the teacher's role is of a facilitator. As the role play proceeds, the learners may feel that they lack certain words or language; at this point the teacher may give some new words or a language to them. This role makes the teacher act as a kind of a facilitator. At the same time the evaluation of the class and offering help when it is necessary is also important.

The second role of the teacher is being a spectator. His/her task is to watch the role-play and then give remarks and advice at the end of the performances. The teacher will walk round the classroom and listen to what the students talking. The teacher at the same time shall note down the mistakes committed by the students. Once the role play is over, the teacher can discuss and correct, if required, the different mistakes done by the learners. For 
this the teacher can also take some corrective measures like giving some remedial task that he or she had predicted would be needed.

Third - After the completion of the role play, audience should guess the proverb being enacted based on the message given, if the proverb is guessed the group gets a point. If the audience can't make a guess or makes an incorrect guess the group gets a negative point.

Fourth- the teacher should be given liberty to decide the time limit for the role play. Within the given frame of time all the group members have to discuss the proverb, select one out of the ten and develop a theme which conveys the message of the proverb. Thereafter, the script is created. The group that completes the script within the time gets one point.

Fifth- every group should be awarded marks for activities like eye-contact, intonation, modulation, pronunciation, clarity of voice, confidence, body language, sense of involvement in the character, dialogue delivery which all reflect the ability and capacity of the group to comprehend the facts. Sixth- At end of the session there can be a small interactive session where responses generated by the audience regarding the accuracy of enactment and possibilities of improving the same are reviewed. This will create a conducive atmosphere amongst the learners of the language. Thus, Role-play seems to be an important tool in teaching speaking skills. Although there is no one definition of role-play and there are some weak points about that activity, its ${ }^{e e}$ numerous advantages far outweigh the disadvantages.

\section{Purpose- Why do we need a role play?}

As we know a role play works at all levels, up to and including undergraduate level and can be adapted to accommodate a wide variety of demands and levels of detail. Role playing is an active learning technique in which students act out situations under the guidance of a teacher or a facilitator. In each scenario, the students take on a role and act out the scene as though it were real. The major benefits are:

- They help students develop an understanding of the complexity of past situations, a much greater complexity because they are, for a lesson, taking part in the historical event.

- They stimulate effective reading, especially at a level and above

- They help students to care about the people in the past because they identify with parts they and their friends have played.

-They are an effective introduction to people, names, a sequence of events and places
- Students take on a decision making persona that might let them diverge from the confines of their normal selfimposed limitations or boundaries.

- They develop students' understanding of the motives and attitudes of people in the past

- Students can transcend and think beyond the confines of the classroom setting

- Students can clearly see the relevance of the content in for handling real world situations if not in the current situation but in future.

- In fact a Student engages himself in higher order thinking and consequently he learns the idea in a better way of comprehension, this becomes more beneficial to the students if the instructor selects and creates useful scenarios during setting the parameters of the role play. Role playing is a social activity. Every player interacts with his fellow players in a given situation or theme. This interaction promotes individuals to come together in order to find solutions and at the same time they come to know what the colleagues think in a particular situation.

- Role play also prepares the students for Real Life. There can be situations similar to real life, and here lies the importance of role play which prepares the students to face the problems with courage and tactics in real life.. At the same time it's very easy for the participants to improve their performance at any sage, as they get the feedback immediately after the role-play

- Role playing allows much of the hypothetical nature of training to be removed, so that the leader of the session can see how others react.

- Here it is important that the trainers can improve the weaknesses of an individual's through proper discussion and suggestions. Creates zeal in the student for learning language and ignites his/her creativity

- The world of the classroom is broadened to include the outside world-thus offering a much wider range of language opportunities.

- Encourages self awareness

\section{CONCLUSION}

It is obvious for a teacher to know the performance of his students. In terms of the usage of language during the role play, this is crucial to know how our students use the language and how can we help them overcome their shortcomings - both in written and spoken. It's so because during an individual presentation the speaking skill becomes most valuable and of utmost importance, be it an interview or even a group presentation before the audience. At this point it becomes obvious that the 
approach we are looking to use for the enhancement of the students' command over spoken language, as it is the need of the hour to grow with the fast-changing world. Both professionally and academically, English, especially spoken English has a key role in one's prospective and career goals. Special attention needs to be given to the rural students whose English background is not up to the mark, because they have limited exposure of the language. Moreover, they have a kind of hesitation and phobia for the language. Most of the agricultural students come from rural areas with rustic family backgrounds, who are the first generation users of this language. In such a condition the role of the teacher is very important at both ends; first cater the language needs of the students and enhance hi/her confidence with approaches like mock interviews or roleplay to boost their confidence and make them ready to face the competition of the job market.

A recent study clearly reflects that only 25 to $30 \%$ of the total Agricultural students in our country have satisfactory command over language skills. The remaining lot of students struggle with their short comings and hence it affects their employability in the modern context. Proficiency in English, now a days, is considered more of a 'Qualifying Criteria' than selection criteria for professional roles in the Agri-industry. In order to make language teaching a joyful as well as challenging activity a teacher can put his efforts to explore a range of verities of approaches. Role play is just one of such methods available for this purpose. It results in a complete development of a student. Their inner culture thus ignited will come out in various ways which promote the upcoming of service minded youth. Therefore, paying active attention by the teachers and honest participation of the students can make language learning a joyful activity in the classroom and at the same time an act of rewarding and encouragement. What is needed most is the selection of proper approach with whole hearted efforts for its implementation from both the sides, in order to attribute the desired results.

\section{REFERENCES}

[1] Dummett, Paul. 1994. "Simulations and realistic tasks", Modern English Teacher 3(1),

[2] Gołębiowska, Aleksandra. 1987. Let's talk: A book for teachers. Warszawa:

[3] International journal of Engg. Edu., 15, 2,PP.,115121(1999).

[4] Larsen-Freeman, Diane(1986), Techniques and Principles in Language Teaching. Oxford: Oxford University Press.

[5] The Internet TESL Journal, Vol. VII, No.7, July-2001. Keane, A and Gibson, I.S. Communication

[6] The Internet TESL Journal, Vol.V, No.4, April
$1999<$ http://itesli.org 